\title{
Annual Editor Report 2019
}

\author{
Felipe Ramos ${ }^{1}$, Editor-in-Chief \\ Fabio Motoki ${ }^{1}$, Co-Editor
}

\section{INTRODUCTION}

In the hopes of creating a tradition, we bring you the second Annual Editor Report from Brazilian Business Review. Differently from the previous one, this report has been written jointly by me, Felipe Ramos, BBR's new Editor-in-Chief, with now Co-Editor Fabio Motoki. It will be an honor to serve as Editor-in-Chief of BBR for years to come. Enjoy the reading!

\section{EDITORIAL PROCESS}

BBR's foremost challenge has not changed: it is to attract and publish high-quality academic research in business. We are happy that BBR has attracted lots of attention from the public. We have been invited to speak about our editorial process, experience, and views at some of Brazil's main conferences, such as EnANPAD (Meeting of the National Association of Postgraduation and Research in Administration), SemeAD (Seminars in Administration from the University of São Paulo), and AdCont (National Congress of Administration and Accounting from the Federal University of Rio de Janeiro).

As a generalist journal, BBR has a team of associate editors that covers a broad spectrum of the business area. The current team is a mix of very experienced researchers, recognized as references in their areas, and younger professors who have shown a distinguished capacity of conducting highquality research. We trust this highly qualified editorial board to decide the fate of their assigned manuscripts and curating contents of great interest to the academic community. The results of this strategy are twofold: BBR is one of the most respected and accessed journals in the area in Brazil, and, consequently, authors consider it a potential channel for their high-quality research.

${ }^{1}$ FUCAPE Business School, Vitória, ES, Brasil 
BBR also has a policy of rotating its editors, including the Editor-in-Chief (EIC). The EIC has a two-year term, after which he becomes a co-editor. This is the process that is taking place now. This policy ensures that the journal has a smooth transition, preventing the loss of knowledge and any structural breaks on its processes. Associate editors (AEs) are also rotated, refreshing the editorial board and opening space for rising researchers from time to time. Although this renewal process has its costs, its benefits are worth it. It brings a fresh mindset, opening the journal to new ideas and different intellectual viewpoints.

BBR has kept the possibility for authors to suggest potential reviewers to be assigned to their manuscript. There is also an option to recommend the exclusion of potentially conflicted reviewers. Even if the suggestions are not accepted, it helps the AE in selecting qualified reviewers for the paper.

\section{ANNUAL ACTIVITY AND ACCEPTANCE/REJECTION RATES}

Table 1 compares the same period ( $\mathrm{Jan} 1^{\text {st }}$ to Nov $30^{\text {th }}$ ) of 2018 and 2019 in terms of manuscripts received. BBR has managed to maintain about the same number of new submissions, with a slight increase on the percentage of rejections from $71 \%$ to $74 \%$. This shows BBR's commitment with quality, selecting only the most interesting papers.

Table 1

Manuscripts received 2018-2019

\begin{tabular}{cccccccc}
\hline \multicolumn{7}{c}{ Annual Outcome Summary - By Journal Year Annual Cohort } \\
\hline Year & $\begin{array}{c}\text { New } \\
\text { Submissions } \\
\text { Received } \\
\text { (a) }\end{array}$ & $\begin{array}{c}\text { Number of } \\
\text { Rejections } \\
\text { (b) }\end{array}$ & $\begin{array}{c}\text { Percentage of } \\
\text { Rejections } \\
\text { (c) }=(\mathrm{b}) /(\mathrm{a})\end{array}$ & $\begin{array}{c}\text { Number of } \\
\text { Papers in } \\
\text { Process } \\
\text { (d) }\end{array}$ & $\begin{array}{c}\text { Percentage in } \\
\text { Process } \\
(\mathrm{e})=(\mathrm{d}) /(\mathrm{a})\end{array}$ & $\begin{array}{c}\text { Number of } \\
\text { Acceptances } \\
(\mathrm{f})\end{array}$ & $\begin{array}{c}\text { Percentage of } \\
\text { Acceptances } \\
(\mathrm{g})=(\mathrm{f}) /(\mathrm{a})\end{array}$ \\
\hline 2018 & 198 & 140 & $71 \%$ & 23 & $12 \%$ & 36 & $18 \%$ \\
2019 & 183 & 136 & $74 \%$ & 24 & $13 \%$ & 26 & $14 \%$ \\
\hline
\end{tabular}

Table 2 breaks down the total of manuscript decision letters sent. The major phase of rejection is in the first round, when both the Editor-in-Chief and the Associate Editor conduct the desk review process. At this point of the editorial process, there are two foremost worries: the viability of the research in terms of incremental contribution and adequateness of the method to answer the research question.

Notice that there is a slight improvement in 2019, of about 3 percentage points. In last year's Annual Report, we highlighted the importance of clearly stating the paper's contribution. We have changed the submission guidelines to make the point, and also have made publicly available the reviewers' guidelines. Thus, we invite our authors to come up with well-thought, crystal-clear contributions, leading to a higher acceptance rate on the first round. However, lack of clear or proper contribution still is the most common reason for rejection.

This year we have also seen good ideas poorly implemented, in the sense that the method chosen was not adequate to reach the research's goal. Finally, poor text has not been a determinant per se in the rejection of papers, as we have been focusing on the interest of the theme. However, it has definitely sealed the fate of papers in which the contribution was not that clear. Therefore, we reinforce the importance of a reasonably well-written text, so that you can properly communicate the value of your research. 
Table 2

Manuscript decisions - 2018

\begin{tabular}{|c|c|c|c|c|}
\hline Decision Outcomes & 2018 & & 2019 & \\
\hline Decision Letter Sent & 270 & & 233 & \\
\hline First-Round Outcomes & 207 & & 174 & \\
\hline Accept & 0 & $0 \%$ & 0 & $0 \%$ \\
\hline Revise \& Resubmit & 52 & $25 \%$ & 48 & $28 \%$ \\
\hline Reject & 155 & $75 \%$ & 126 & $72 \%$ \\
\hline Second-Round Outcomes & 46 & & 41 & \\
\hline Accept & 24 & $52 \%$ & 15 & $36 \%$ \\
\hline Revise \& Resubmit & 19 & $41 \%$ & 20 & $49 \%$ \\
\hline Reject & 3 & $7 \%$ & 6 & $15 \%$ \\
\hline Third and Later-Round Outcomes & 17 & & 18 & \\
\hline Accept & 13 & $76 \%$ & 11 & $61 \%$ \\
\hline Revise \& Resubmit & 4 & $24 \%$ & 3 & $17 \%$ \\
\hline Reject & 0 & $0 \%$ & 4 & $22 \%$ \\
\hline
\end{tabular}

This year it became rarer for a paper to be accepted at the second round (drop from $52 \%$ to $36 \%$ ), with an increase of the level of R\&Rs. In turn, the rejection rate doubled, with authors not properly addressing all the issues listed by the reviewers or missing the deadline. We reinforce the importance of properly responding to the issues contained in the review. You are not forced to accept or comply, since they are recommendations, but whenever you do not agree with a specific issue, you must clearly state why, providing scientific evidence to back your claims. Remember that the review process is a dialogue between authors, editors, and reviewers, in which theses are defended with science.

\section{PROCESSING TIMES}

BBR's average time between submission and acceptance went from about 160 to 199 days. Bear in mind that a perfect first-round takes more than 100 days from submission to $R \& R$, and half of second-rounds go into third and later rounds. Therefore, the increase still is within parameters, and reflect the increases in proportion of R\&Rs on first and second rounds. The numbers show that BBR is committed to providing feedback to authors as soon as possible, while still maintaining a high-quality evaluation process.

\section{BBR'S REACH}

In 2019 BBR's contents from 2018 and 2019 has been indexed by Scopus. We have requested a backfill request, so that the all articles, from the very beginning, are indexed as well. In 2019 we have also requested indexing by Web of Science, and we are currently waiting for Clarivate's assessment. These initiatives will expose BBR's articles to a more international audience, and in the long term should leverage both citations and submissions.

Figure 1 displays updated stats from Redalyc. It contains Business Administration \& Accounting journals from Brazil ranked as A2 by the Brazilian Ministry of Education (the same rank as BBR) that are indexed by Redalyc. BBR still has the most article downloads, more than 642,000 . Its level of internationalization (lower is better) is still in line with most Brazilian periodicals of the A2 stratum, despite the diversity of authors' countries is lower than most. 
BBR

17

IV

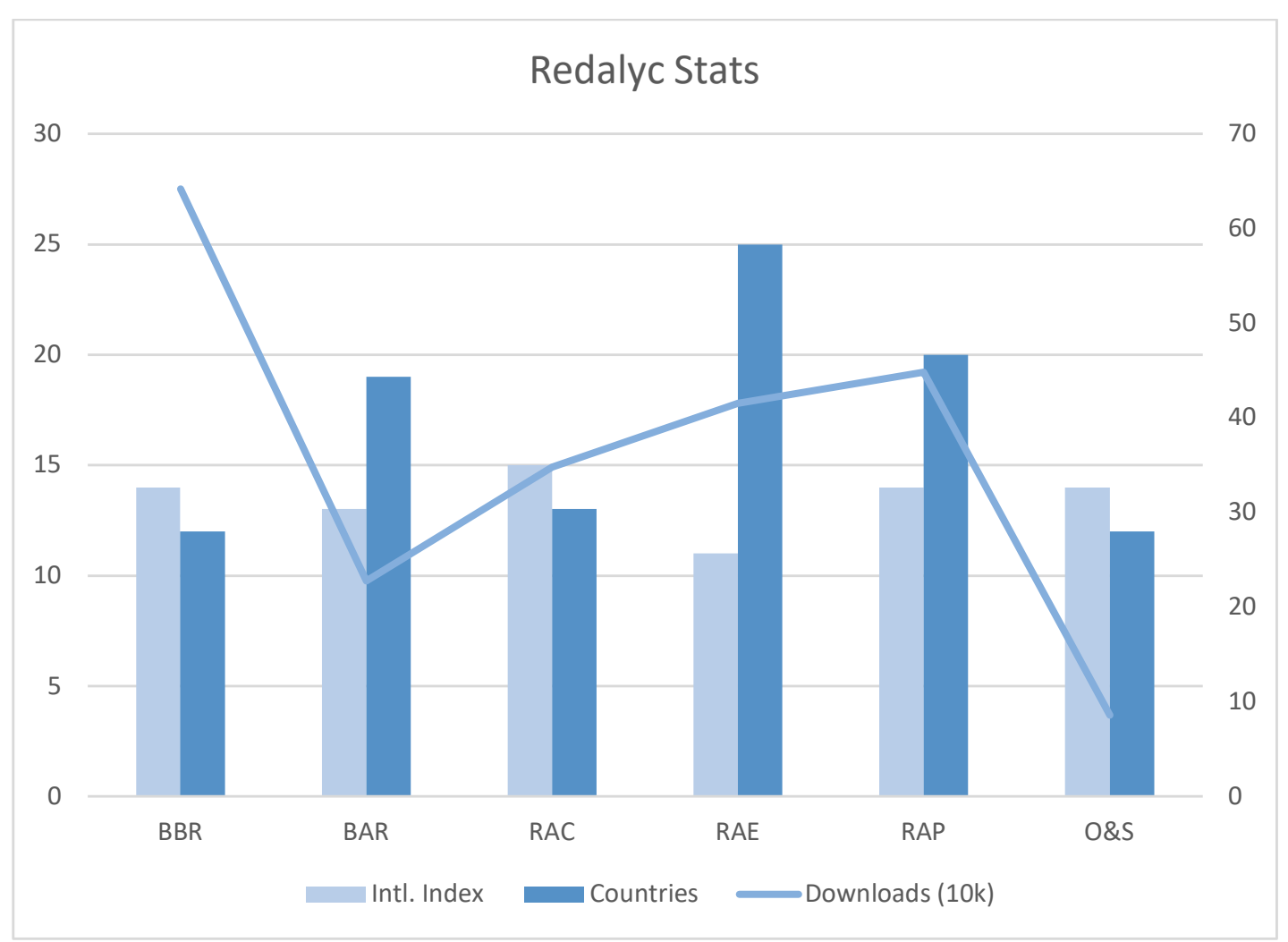

Figure 1. Selected Redalyc stats on Brazilian journals - 2019

Notes: BBR is Brazilian Business Review. BAR is Brazilian Administration Review. RAC is Journal of Contemporary Administration. RAE is Journal of Business Management. RAP is Brazilian Journal of Public Administration. O\&S is Organizaçóes \& Sociedade. Intl. Index is a conversion to a decimal scale from 0 (most international) to 24 (least international) of the two-tier classification of Redalyc. Each level goes from 1 to 5 (1 is more international) and measures the diversity of authors' nationalities and how important is the participation of international authors in the journal's published articles (Redalyc, n.d.). For instance, BBR's classification is $3^{5}$, which translates into 14 in the graph. Countries is the number of distinct authors' countries who have published. Downloads is the number of downloads (in tens of thousands, secondary right-hand axis) recorded in Redalyc. CV\&R (Contabilidade Vista \& Revista), RCC (Revista Contemporânea de Contabilidade), RBGN (Review of Business Management), RCF (Accounting \& Finance Review), RCO (Journal of Accounting and Organizations), and RUC (Journal of Accounting) have been dropped due to lack of data in Redalyc.

Since the new website launch, in Jul/2018, to Nov/2019, BBR's website has received almost 29,000 different users. During this period, there were almost 160,000 page views. About $70 \%$ of the traffic came from Brazilian addresses. The remaining 30\% came from several countries, with the most common being the US (8.91\%), India (1.67\%), and the UK (1.5\%). Portugal fell from $3^{\text {rd }}$ to $4^{\text {th }}$ place $(1.29 \%)$ in comparison with the last annual report. This diversity corroborates our perception that is of utmost importance that BBR remains a bilingual journal. Figure 2 shows the countries with the most accesses, ex-Brazil. 

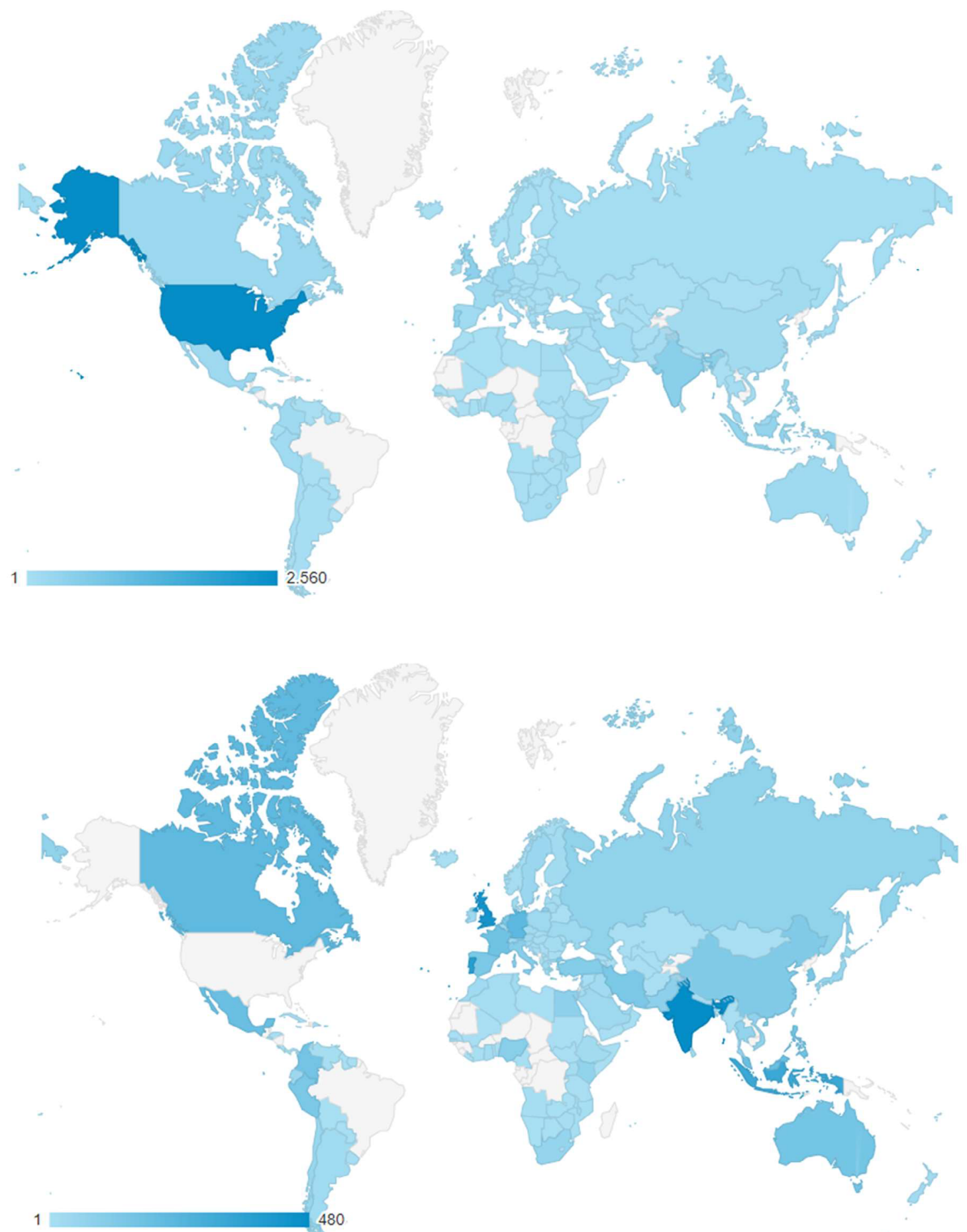

Figure 2: Google Analytics statistics for BBR users, excluding Brazil, and excluding Brazil and the US. 
BBR

17

VI

\section{ACKNOWLEDGEMENTS}

This year we have had two editorial assistants. Patricia gave birth to a healthy girl, Mai, and went on maternity leave for 4 months. She has just returned. During this period Rubia Bottacine substituted Patricia. We thank both for the seamless transitions, both have done a great job in keeping the editorial process running smoothly. A special thanks to Rubia for accepting the challenge!

Our Associate Editors have kept their deep commitment to BBR. Our newcomer Juliana Kopp has performed beautifully. We cannot thank you enough for granting us part of your very precious time and knowledge. We also extend our deep thanks to our almost 130 reviewers of 2019, who also donated these extremely valuable assets to BBR. Constantly the authors praise BBR's smooth evaluation process, and surely our editors, our reviewers, and our editorial assistant are key to this. A roster with all 2019 reviewers follows in Appendix A.

Of course, we cannot forget our authors. We have received many deeply interesting studies, some of them with intriguing themes. The trust you deposit in BBR is heartwarming, helping BBR maintain its position as one of the main Brazilian outlets for high-quality research in business.

I specially thank Fabio Motoki for the dedication placed in recent year at BBR. As a frequent reader and former associate editor, I realize the great advances that $\mathrm{BBR}$ made during his tenure. Fabio Motoki is one of the great professionals I have had the opportunity to work with.

We also reaffirm our gratitude to our Supporting Institution, FUCAPE Business School, and $\mathrm{CNPq}$, for providing part of the financial resources needed by BBR. Last, but not least, Fabio thanks his wife Patricia (who is also Patricia Motoki, but it's not our editorial assistant!) for her support and understanding.

\section{REFERENCES}

Redalyc. (n.d.). Metodología. Retrieved December 27, 2019, from https://www.redalyc.org/ revista.oa?id=1230\&tipo=indicadores 
Vieira, Valter

Alves, Helena

Antonello, Claudia

Backes, Danieli

Barbachan, Jose

Barcelos, Vinicius

Barros Estivalete, Vania

Bastos, Sérgio

Beiruth, Aziz

Bergmann, Daniel

Borchardth, Miriam

Borges, Gustavo

Bortolon, Patricia

Braga, Ana

Brambilla, Flávio

Brunstein, Janette

Cabral, Patricia Martins Fagundes

Callado, Aldo

Carvalho, Juliana

Castro Martins, Henrique

Cavalcante, Paulo

Corso, Jansen

Costa, Isabel

Costa, Cristiano

Costa, Fábio

Costa, Luciana

Craide, Aline

Crisóstomo, Vicente

Cruz, José Elenilson

Cyrino, Alvaro

d'Angelo, Marcia

da Cunha Araújo, Rebeca Cordeiro

Damasceno, Felipe

Dantas, José

De Luca, Marcia

de Souza-Leão, André Luiz

De Toni, Deonir

Dieng, Mamadou

Domingues, Maria

dos Santos, Marco Aurélio

Duarte, Filipe

Fantinel, Letícia

Farias, Milton

Farias, Salomao

Fernandes, Cleverton
Fernandes, Cristina

Figueiredo, Ronnie

Filho, Edson

Finger França Maluf, Luiz Augusto

Fortunato, Graziela

Franco, Mário

Freitas, Flávia

Furquim, Nelson

Furtado, Liliane

Galdi, Fernando

Gallon, Shalimar

Garcia, Fabio

Godoy, Leoni

Gonçalves, Miguel

Graeml, Alexandre

Herrera, Milton M.

Iquiapaza, Robert

Junior, Luiz

Klann, Roberto

Klotzle, Marcelo

Lacruz, Adonai

lage, Mariana

langen, peter $\mathrm{d}$

Laurett, Rozélia

Leal, Carmem

Lopes, Evandro

Lucena, Wenner

Macedo, João Marcelo

Mansur, Juliana

Marchetti, Renato

Marchiori, Danilo

Marques, Carla

Martins, Orleans

Matos, Paulo

Menezes, Vanessa

Miragaia, Dina

Modenesi, Daniel

Moll Brandão, Marcelo

Monte-Mor, Danilo

Mott, Michel

Moura, André

Moura, Elton

Moura, Ralf

Nakao, Silvio

Navarro-García, Antonio 
BBR

17

VII
Neto, Octavio

Neto, Silvio

Nossa, Valcemiro

Nunes, Alcina

Odete, Paula

Oliveira, Hallysson

Oliveira, Lucia

Pacheco, Andressa

Paço, Arminda

Pimentel, Rene

Pimentel, Ricardo

Ramírez-Hurtado, José M.

Rezende, Sergio

Rodrigues, Andrea

Rodrigues, Evaldo César

Rodrigues, Ricardo

Russo, Paschoal Tadeu

Sarquis, Aléssio
Semprebon, Elder

Serra, Fernando

Silva, Alfredo

Silva, Anielson

Silva, Cinthia

Silva, Dirceu

Silva, Hermes

Simóes, Jorge

Souza, Ariana

Tardin, Neyla

Teixeira, Arilda

Tristão, José

Versiani, Ângela

Vianna Brugni, Talles

Vieira, Elsa

Vieira, Guilherme Bergmann Borges

Zambelli, Amanda 